https://www.journal-imab-bg.org

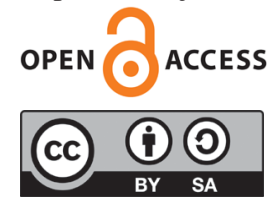

Original article

\title{
MEDICAL SPECIALISTS AND ETHICS COMMITTEES IN HEALTHCARE ESTABLISHMENTS IN BULGARIA
}

\author{
Neli Gradinarova ${ }^{1}$, Emilian Radev ${ }^{2}$, Natalia Shtereva-Nikolova ${ }^{3}$ \\ 1) Department of Medical Ethics and Law, Faculty of Public Health, Medical \\ University - Sofia, Bulgaria \\ 2) Department of Prevention, Faculty of Public Health, Medical University- \\ Sofia, Bulgaria \\ 3) Department of Medical Ethics and Law, Faculty of Public Health, Medical \\ University - Sofia, Bulgaria.
}

\section{ABSTRACT:}

The legal framework in the Republic of Bulgaria governing the structure and the activity of ethics committees in the area of healthcare is contained in the laws and regulations in force. Ethics committees provide assistance to the medical and non-medical staff in healthcare establishments, to the patients and their families and friends, by helping them to resolve matters occurring on a daily basis. Ethics committees are an independent consultative body that provides opinions and assessments on cases concerning ethical issues arising in day-to-day practice in healthcare establishments.

In 2017 , a survey was carried out with the participation of 149 medical specialists from three healthcare establishments in Bulgaria, where the purpose was to assess the awareness of the medical specialists of the existing and active ethics committees in the country. Based on the outcomes of the survey from 2017 and in execution of a project on the subject "Improvement of the access to ethics committees through training of medical specialists and patients in healthcare establishments in Bulgaria”, GRANT 2018, Contract No.D-98/03. 05. 2018 and Project with ref. No.7757/22. 11. 2017, three hundred information guides were drawn up and printed in order to be distributed and to inform medical specialists in healthcare establishments. In the period from 01. 07. 2018 until 01. 09. 2018, following the training and information campaign under Grant 2018, Contract No.D-98/ 03.05.2018, a consecutive survey was carried out, in which 213 medical specialists were surveyed.

The above surveys have indicated that the need for a change and improvement of the awareness of the medical specialists of the ethics committees operating in Bulgaria is immense. Healthcare establishments in Bulgaria should improve their information channels in regard to the existence of the ethics committees and the benefits of their activity. Such change would result in an improvement of the quality of the provided healthcare services, and on its turn this would lead to better health of the Bulgarian citizens. Bulgaria,

Keywords: medical specialists, ethics committees,

\section{INTRODUCTION:}

Morality has a yet growing role in healthcare and the responsible ethical behaviour is seen as a prerequisite for preventing and combating a number of moral risks in society [1,2]. Codes of Ethics are a mechanism to control moral risk and responsibility; they have a preventive function by reinforcing moral responsibility and help to avoid unfavourable outcomes. Codes of Ethics present the values and the principles of different communities and groups and on their basis ethics committees are formed.

The legal framework in the Republic of Bulgaria governing the structure and the activity of ethics committees in the area of healthcare is contained in the laws and regulations in force. The activity of ethics committees is governed by the Bulgarian Constitution as well as a number of regulations transposing the respective directives adopted by the EU. The Health Law, the Law on Medicinal Products for Human Use and the Law on Medical Devices are key laws in this area. In addition to the laws and regulations, there are also a number of codes of ethics that set up rules and principles of conduct in clinical research, as well as the Code of Professional Ethics, the Code of Ethics of the Bulgarian Association of Clinical Research and the codes of ethics of the research pharmaceutical industry and the generic pharmaceutical manufacturers.

Ethics committees which are set up in healthcare establishments have the purpose of assisting doctors and other medical and non-medical staff in the hospital, the patients and their families and friends to resolve the ethical and legal matters that they face on a daily basis [3]. They serve as a point of reference in resolving disputes in the area of medical ethics [4]. The activity of the ethics committees, which have been set up and are operating in the healthcare establishments in Bulgaria, is governed by the Internal Rules of Procedure of the relevant healthcare establishment or the director of the healthcare 
establishment can approve and adopt separate Rules of Procedure of the ethics committee. The act that sets out the functions and the powers of the ethics committees specifies the implementation of the legal acts governing the protection of the rights, the safety and wellbeing of the patients, the medical specialists in the healthcare establishment and the participants in research carried out on the premises of the healthcare establishment. The regulated rules guarantee the observance of high standards of ethical behaviour by all parties involved in the medical and diagnostic process and in the full realisation of medical activities as well as the researchers and the members of research teams at every stage of research carried out at the healthcare establishment.

Ethics committees are an independent expert and consultative body providing assessments and opinions on the ethical aspects of the provided medical services, as well as the ethical aspects of research activities in the healthcare establishment [5]. Ethics committees in healthcare establishments prepare opinions on claims by patients and their representatives and carry out inspections in the event of unethical relationships between the hospital staff and patients or between the hospital staff and the trainee students and post-graduates in the healthcare establishments [6]. Their function is to protect the patients, the staff in the healthcare establishment and the healthcare establishment itself, through assisting and encouraging the medical specialists to share more information with the patients so that they are more involved with their own health and treatment, and also to develop standards for action and decision-making on macro and micro levels.

In 2017, a survey was carried out with the participation of 149 medical specialists from three healthcare establishments in Bulgaria, where the purpose of the survey was to assess the awareness of the medical specialists of the existing and active ethics committees in the country. The medical specialists were asked to answer the question "Do you know what types of ethics committees exist in Bulgaria?" where only $29.5 \%$ of the respondents confirmed that they knew that ethics committees exist and are active in the healthcare establishments. To the question "Do you know what are the powers and the responsibilities of ethics committees?" $23.5 \%$ of the medical specialists indicated that they had no information about the rights and the responsibilities of ethics committees. To the question "Do you know when ethics committees can be referred to?" more than half of the working medical specialists (51\% of those surveyed) indicated that they did not know when ethics committees could be referred to. The results from the survey have identified a low level of awareness of the healthcare specialists in Bulgaria in regard to the ethics committees in the area of healthcare and an imperative need for a change. The lack of information becomes a fundamental obstacle to the existence and functioning of the ethics committees in healthcare establishments. In fact, the existence of ethics committees is quite limited and is only theoretical, whereas their efficient functioning would benefit both the medical specialists and the patients in the country.

The purpose of this article is to employ the results from the survey from 2017 and through information campaigns and a consecutive new survey to check the dynamics of the matter and through an analysis of the performed actions and the results to analyse the ways for raising the awareness of the medical specialists in regard to the ethical committees in the country.

\section{MATERIALS AND METHODS:}

Based on the outcomes of the survey from 2017 and in execution of a project on the subject "Improvement of the access to ethics committees through training of medical specialists and patients in healthcare establishments in Bulgaria”, GRANT 2018, Contract No. D- 98/03. 05. 2018 and Project with ref. No. 7757/22. 11. 2017, three hundred information guides were drawn up and printed in order to be distributed and to inform medical specialists in healthcare establishments. The information guides were handed out to working medical specialists from those three healthcare establishments, where earlier in 2017 the survey was carried out with the purpose to check whether the level of awareness about the ethics committees has improved and whether this should become a nationwide campaign, or the need for a change calls for other measures, such as to introduce in the curriculum of future doctors and medical specialists additional law and ethics academic disciplines that should include information on ethics committees and the benefits of their activity. The awareness of the medical specialists is a prerequisite for the efficient functioning of the ethics committees in the area of healthcare.

In the period from 01. 07. 2018 until 01. 09. 2018, following the training and information campaign under Grant 2018, Contract No. D-98/03. 05.2018, a consecutive survey was carried out with the participation of 213 medical specialists working at the following healthcare establishments in Bulgaria: MBAL (Multiprofile Hospital for Active Treatment) Doverie - Sofia, First MBAL (Multiprofile Hospital for Active Treatment) - Sofia EAD and MBAL (Multiprofile Hospital for Active Treatment) Dr. Atanas Dafovski AD - Kardzhali. The choice of those healthcare establishments was not accidental, as those were the same healthcare establishments where in 2017 the previous survey was carried out, again putting a focus on the medical specialists and aiming to assess their awareness of the ethics committees in the area of healthcare.

In 2017,149 medical specialists took part in the survey, of which $15.4 \%$ were men and $84.6 \%$ were women, and in 2018, 213 medical specialists were surveyed, of which $23.5 \%$ were men and $76.5 \%$ were women. Despite the fact that the survey done in 2018 has seen an increased interest and readiness to participate in the survey on the part of the male medical specialists, the female respondents still continue to demonstrate greater willingness to participate in social and statistical surveys. Following the information campaigns and the distribution of the infor- 
mation guides, a consecutive survey was done which included some of the questions used in 2017, where the purpose was to be able to make a comparison after the processing of the results. Both surveys, in 2017 and in
2018, have asked the medical specialists to confirm whether they were familiar with the types of ethics committees that exist in Bulgaria (Table 1).

Table 1. Level of awareness of the medical specialists in 2017 and 2018 of the types of ethics committees

\begin{tabular}{|l|c|c|c|c|}
\hline \multirow{2}{*}{$\begin{array}{l}\text { Do you know what types of ethics } \\
\text { committees exist in Bulgaria? }\end{array}$} & \multicolumn{2}{|c|}{2017} & \multicolumn{2}{|c|}{2018} \\
\cline { 2 - 5 } & $\mathrm{n}$ & $\%$ & $\mathrm{n}$ & \multicolumn{2}{c|}{$\%$} \\
\hline Ethics committees in healthcare establishments & 44 & $29,50 \%$ & 36 & $16,90 \%$ \\
\hline Ethics committees for research in medical universities & 18 & $12,10 \%$ & 12 & $5,60 \%$ \\
\hline Ethics committee for multi-center trials & 9 & $6,10 \%$ & 8 & $3,80 \%$ \\
\hline Ethics committee for research & 14 & $9,40 \%$ & 10 & $4,70 \%$ \\
\hline $\begin{array}{l}\text { Ethics committees to the Bulgarian Medical Association }, \\
\text { the Bulgarian Dental Association, } \\
\text { the Bulgarian Nursing Care Association }\end{array}$ & 38 & $25,50 \%$ & 41 & $19,20 \%$ \\
\hline All committees listed above exist & & & \\
\hline Some of the committees listed above exist & 54 & $36,20 \%$ & 78 & $36,60 \%$ \\
\hline Have no information & 23 & $15,40 \%$ & 42 & $19,70 \%$ \\
\hline
\end{tabular}

The above table shows that in $201729.50 \%$ of the surveyed medical specialists responded that they were aware of the existence of ethics committees in healthcare establishments, while in 2018 only $16.90 \%$, which is only 12 people out of a total of 213 medical specialists, responded that they were aware of the existence of ethics committees in healthcare establishments. The decrease in the awareness among the medical specialists can be noted as a trend also in the other responses in the survey: ethics committee for multi-center trials $(6.10 \%$ in 2017 and $4.70 \%$ in 2018), ethics committees to the Bulgarian Medical Association, the Bulgarian Dental Association and the
Bulgarian Nursing Care Association (25.50\% in 2017 and $19.20 \%$ in 2018). Despite the information meetings and campaigns, and the distributed information guides in all three healthcare establishments, the awareness of the medical specialists in regard to the matter has not only failed to improve, but we even notice decreasing awareness of the respondents.

In the surveys done in 2017 and in 2018, the medical specialists were asked whether they knew when ethics committees could be referred to in the course of the medical practice (Table 2).

Table 2. Awareness of the medical specialists, reported in 2017and 2018, of the possibilities for referral to the ethics committees

\begin{tabular}{|l|c|c|c|c|}
\hline \multirow{2}{*}{$\begin{array}{c}\text { Do you know when ethics committees can be referred } \\
\text { to in the course of the medical practice? }\end{array}$} & \multicolumn{3}{|c|}{ year } \\
\cline { 2 - 5 } & $\mathrm{n}$ & $\%$ & \multicolumn{3}{|c|}{2018} \\
\hline Yes & 73 & $49,00 \%$ & 122 & $57,30 \%$ \\
\hline No & 75 & $50,30 \%$ & 90 & $42,30 \%$ \\
\hline In cases when $\ldots$ & 1 & $0,70 \%$ & 1 & $0,50 \%$ \\
\hline
\end{tabular}

Table 2 presents and compares the responses to the question "Do you know when ethics committees can be referred to in the course of the medical practice?", given by the medical specialists in the surveys from 2017 and 2018. In 2017,78 respondents representing $49 \%$ of the medical specialists responded positively to the question and in 2018, 122 respondents representing 57.30\% responded that they were informed about the options for re- ferral to the ethics committees. In regard to this question, there is an improvement of the awareness of the medical specialists and although the change is not so significant in percentage terms, we should note this positive trend.

In both surveys the medical specialists were asked whether they think that ethics committees should exist (Table 3). 
Table 3. The opinion of the medical specialists, reported in 2017 and 2018, on the need for ethics committees to exist

\begin{tabular}{|l|c|c|c|c|}
\hline \multirow{2}{*}{ Do you think that ethics committees should exist? } & \multicolumn{3}{|c|}{ year } \\
\cline { 2 - 5 } & $\mathrm{n}$ & $\%$ & $\mathrm{n}$ & \multicolumn{2}{|c|}{2018} \\
\cline { 2 - 5 } & 43 & $29,10 \%$ & 85 & $39,90 \%$ \\
\hline Yes, the benefits of their activity are significant & 53 & $35,80 \%$ & 58 & $27,20 \%$ \\
\hline $\begin{array}{l}\text { Yes, although I do not think they bring any } \\
\text { benefits to doctors }\end{array}$ & 9 & $6,10 \%$ & 18 & $8,50 \%$ \\
\hline No & 43 & $29,10 \%$ & 52 & $24,40 \%$ \\
\hline Cannot decide & & & 52 \\
\hline
\end{tabular}

In 2017,43 respondents $(29.10 \%$ of the total number of respondents) responded that in their opinion ethics committees should exist as the benefits of their activity are significant, whereas in 201885 respondents (39.90\% of the total number of respondents) responded in the same way. Despite the controversial responses presented in the above table and the insufficient awareness of the medical specialists, the positive attitude toward the functioning ethics committees and the benefits of their activity is present.

\section{CONCLUSIONS:}

Healthcare establishments in the Republic of Bulgaria are a key element in the national healthcare system [7] and the ethics committees that operate on their territory guarantee compliance with the modern legislation in the country as well as respect for and observance of the rights of the medical specialists who work on their territory. The conducted surveys have found that the need for a change and improvement of the awareness of the medical specialists in regard to the ethics committees operating in the country is immense. Greater awareness would improve the quality of the provided services and the health of the nation. The information campaign that was carried out and the distributed information guides have rendered unsatisfactory results as to raising the awareness of the medical specialists. The results have indicated that after the campaign more medical specialists believe that ethics committees should exist and the benefits of their activity are significant, and the awareness of the medical specialists in regard to when ethics committees can be referred to has also improved. Despite the positive trends seen in some of the responses, the awareness level in regard to the existing ethics committees in the country still remains low and unsatisfactory. A one-off information campaign and one-off provision of information materials on ethics committees do not suffice and therefore regular training seminars should be organized to discuss general theoretical and practical matters concerning the ethics committees and their activity. Such information campaigns and meetings as well as the relevant information materials should be addressed both to the medical specialists and the patients in healthcare establishments, where greater awareness would facilitate the work and the communication between the staff of the healthcare establishments, the patients and their families and friends and would allow real access to the activity and the benefits from the activity of the ethics committees in healthcare establishments in Bulgaria.

\section{FUNDING}

This publication is a part of the project" Improvement of the access to ethics committees through training of medical specialists and patients in healthcare establishments in Bulgaria" funded by the Council of Medical Science of the Medical University- Sofia, GRANT 2018, Contract No. 98/03. 05. 2018 and Project No. 7757/22. 11. 2017.

\section{REFERENCES:}

1. Pozgar GD. Legal and Ethical Issues for Health Professionals. 3rd Edition. Jones and Bartlett Learning, LLC, 2013; 7p. ISBN 978-1-44964775-9

2. Austin W. What Is the Role of Ethics Consultation in the Moral Habitability of Health Care Environments? AMA J Ethics. 2017 Jun;19(6):595600. [Crossref]

3. Gradinarova N. [Role of ethics committee as a guarantee for proper functioning of health system] [in Russian] VIII International Scientific and Practical Internet Conference "Health condition: medical, social and psychological-pedagogical aspects". 2017 Feb; 703-712

4. Gradinarova N, Trendafilova P. [The necessity for existence of ethics committees for medical specialists in Bulgaria.] [in Bulgarian] 39th Session
Technology Contact 2017 - "The Civil Idea in Action". 2017 Jun;163-169

5. Deliverska M, Gradinarova N. Ethical and legal aspects of functioning of Ethic committees in Bulgaria. $J$ of IMAB. 2017 Apr-Jun;23(2):15871590. [Crossref]

6. Hester DM, Schonfeld T. Introduction to healthcare ethics committees. In: Guidance for Healthcare Ethics Committees. Edited by Hester DM, 
Schonfeld T. Cambridge University Press. 2012; Chapter 1: p.1-8.

[nternet]

7. Valkanova M. [Medical Law.] [in Bulgarian] STENO, Varna. 2014; p.35.

Please cite this article as: Gradinarova N, Radev E, Shtereva-Nikolova N. Medical Specialists and ethics commitees in Healthcare Establshments in Bulgaria. J of IMAB. 2019 Jan-Mar;25(1):2447-2451.

DOI: https://doi.org/10.5272/jimab.2019251.2447

Received: 07/11/2018; Published online: 26/03/2019

Address for correspondence:

Neli Gradinarova,

Department of Medical Ethics and Law, Faculty of Public Health, Medical University - Sofia,

8, Bialo More Str., 1527 Sofia, Bulgaria

E-mail: neli.p.gradinarova@gmail.com 